\title{
EDITORIAL
}

\section{An Introduction From the Co-Chairs of the Wilderness Medical Society Clinical Practice Guidelines Committee}

This supplement of Wilderness \& Environmental Medicine is a special issue comprising Wilderness Medical Society (WMS) clinical practice guidelines (CPGs). This edition contains both newly developed CPGs and updates to our previously published CPG series. Our goal is to provide the most up-to-date and relevant clinical information to frontline providers in wilderness or austere environments. All recommendations are graded based upon the clinical strength of available evidence as outlined by the American College of Chest Physicians (ACCP) (Table 1). ${ }^{1}$

CPGs are increasingly necessary to help clinicians navigate and synthesize the expanding volume of available medical literature. A unified and reliable approach to the development of CPGs has not yet been universally adopted, in large part owing to variability in the quality of evidence available. Well-designed and adequately powered randomized clinical trials (RCTs) lend themselves well to situations where common ailments (eg, diabetes mellitus) can be treated dichotomously (medication vs placebo).
High-quality evidence is far more difficult to obtain in procedural specialties (which are subject to large variations in technique, myriad related biases, and difficulty blinding) or for rare conditions. Certainly, the latter is an inherent challenge in austere medicine. The illnesses and injuries we treat are not only rare, they also occur in challenging and remote environments. For both practical and ethical considerations, it is difficult to design and execute RCTs for the treatment of conditions such as high altitude cerebral edema, venomous reptile bites, or lightning strikes. Even more common conditions such as frostbite, acute mountain sickness, hypo- and hyperthermia, and submersion injuries are relatively infrequently seen and unpredictable in circumstance. The Institute of Medicine (IOM) published guidelines for the development of a standardized approach for objective, scientifically valid, and consistent approaches to developing CPGs in 2008 . $^{2}$ In spite of this, an independent review of 130 CPGs published in 2012 revealed that less than half met more than $50 \%$ of the IOM standards. ${ }^{3}$

Table 1. American College of Chest Physicians classification scheme for grading evidence and recommendations in clinical guidelines

\begin{tabular}{|c|c|c|c|}
\hline Grade & Description & Benefits vs risks and burdens & Methodologic quality of supporting evidence \\
\hline $1 \mathrm{~A}$ & $\begin{array}{l}\text { Strong recommendation, } \\
\text { high-quality evidence }\end{array}$ & $\begin{array}{l}\text { Benefits clearly outweigh risks } \\
\text { and burdens or vice versa }\end{array}$ & $\begin{array}{l}\text { RCTs without important limitations or } \\
\text { overwhelming evidence from observational } \\
\text { studies }\end{array}$ \\
\hline $1 \mathrm{~B}$ & $\begin{array}{l}\text { Strong recommendation, } \\
\text { moderate-quality evidence }\end{array}$ & $\begin{array}{l}\text { Benefits clearly outweigh risks } \\
\text { and burdens or vice versa }\end{array}$ & $\begin{array}{l}\text { RCTs with important limitations or } \\
\text { exceptionally strong evidence from } \\
\text { observational studies }\end{array}$ \\
\hline $1 \mathrm{C}$ & $\begin{array}{l}\text { Strong recommendation, } \\
\text { low-quality or very } \\
\text { low-quality evidence }\end{array}$ & $\begin{array}{l}\text { Benefits clearly outweigh risks } \\
\text { and burdens or vice versa }\end{array}$ & Observational studies or case series \\
\hline $2 \mathrm{~A}$ & $\begin{array}{l}\text { Weak recommendation, } \\
\text { high-quality evidence }\end{array}$ & $\begin{array}{l}\text { Benefits closely balanced with } \\
\text { risks and burdens }\end{array}$ & $\begin{array}{l}\text { RCTs without important limitations or } \\
\text { overwhelming evidence from observational } \\
\text { studies }\end{array}$ \\
\hline $2 \mathrm{~B}$ & $\begin{array}{l}\text { Weak recommendation, } \\
\text { moderate-quality evidence }\end{array}$ & $\begin{array}{l}\text { Benefits closely balanced with } \\
\text { risks and burdens }\end{array}$ & $\begin{array}{l}\text { RCTs with important limitations or } \\
\text { exceptionally strong evidence from } \\
\text { observational studies }\end{array}$ \\
\hline $2 \mathrm{C}$ & $\begin{array}{l}\text { Weak recommendation, } \\
\text { low-quality or very } \\
\text { low-quality evidence }\end{array}$ & $\begin{array}{l}\text { Uncertainty in the estimates of benefits, } \\
\text { risks, and burden; benefits, risk, and } \\
\text { burden may be closely balanced }\end{array}$ & Observational studies or case series \\
\hline
\end{tabular}

RCT, randomized controlled trial.

Source: Guyatt et al. 
The following represents the efforts of the WMS to develop a sound CPG process, based on the principles outlined by the IOM.

Transparency. The WMS will clearly publicize the process by which CPGs are developed. Our CPG committee meetings are open to the WMS membership, and our process will be delineated in editorials such as this communication.

Guideline development and group composition. Guideline panel membership is a main determinant of the trustworthiness of guidelines. ${ }^{4}$ The WMS is committed to ensuring that each CPG is developed by a working group representative of the best experts in the field and multidisciplinary in scope. The proposed authorship panel for each WMS CPG is approved by the WMS clinical practice guidelines committee. Additional input from the journal's editorial staff and the WMS board of directors is sought to ensure the final panel represents the best expertise in the field. There is no requirement for panel members to be WMS members.

Conflicts of interest. The WMS CPG development protocol requires complete disclosure or real or potential conflicts of interest for all panel members. Panel members with significant conflict of interest are removed from the process.

Use of best evidence available. The WMS is committed to ensuring that each CPG panel, as a whole, possesses a sufficient level of expertise to search, identify, critique, and grade the available evidence to ensure the most inclusive search and identification of the highest level of evidence. The inclusion of supplementary data tables with each CPG attempts to provide further detail regarding the quality of evidence on which each recommendation is based. The periodic revision and updating of each CPG ensures that current literature and thinking are included.

The committee believes the classification scheme developed by the ACCP ${ }^{1}$ offers the best fit for WMS CPGs. Much of the evidence in wilderness medicine is of low quality or small numbers, and our recommendations are often classified as strong or weak based more on the benefit vs risk of an intervention than on the quality of evidence supporting it. The ACCP guidelines offer the ability to assign grades with a description of how the strength of the recommendation is influenced by both evidence and the risk/benefit ratio. Other systems are less clear in this regard, or seemingly equate the strength of the recommendation disproportionately to the strength of evidence. Although a rigid approach may be appropriate in clinical areas where high levels of evidence exist, we believe it is less useful when the preponderance of evidence is of lower quality.
Evidence quality and recommendation strength. For each recommendation, CPGs should provide sound reasoning, meaningful discussion of benefits and risks, and a description of the relative strength of the evidence and the role of subjective judgments. Differences of opinion among panel members are discussed.

Articulating recommendations. CPGs should clearly articulate the action recommended and the circumstances around which action should be taken.

External review. All WMS CPG manuscripts are submitted to Wilderness \& Environmental Medicine and are subject to the same independent, rigorous, single-blinded peer review process as any other submitted manuscript.

Updating. The WMS is committed to timely updating of all CPGs. Authors are expected to keep articles as evidence based and current as possible; thus, some CPGs with new or changing data may be updated more frequently than others.

Feedback. Any feedback on our CPGs can be directed to the WMS CPG committee. Contact information can be found on the WMS website. We will use this feedback to evaluate, innovate, and improve on future CPGs.

We believe that our process represents the best course for the Society to produce timely, relevant, and trustworthy CPGs. Previously published guidelines have been some of the most highly cited articles in Wilderness \& Environmental Medicine. It is our foremost goal to continue the tradition of bringing forward the best available data to the wilderness medical provider.

Christopher Davis, MD

Michael Caudell, MD

Tracy Cushing, MD, MPH

Co-Chairs, Wilderness Medical Society Clinical Practice Guidelines Committee

\section{References}

1. Guyatt G, Gutterman D, Baumann M, Addrizzo-Harris D, Hylek EM, Phillips B, et al. Grading strength of recommendations and quality of evidence in clinical guidelines: report from an American College of Chest Physicians task force. Chest. 2006;129(1):174-81.

2. Graham R, Mancher M, Wolman DM, Greenfield S, Steinberg E, eds. Institute of Medicine of the National Academies. Clinical Practice Guidelines We Can Trust. Washington, DC: National Academies Press; 2011.

3. Kung J, Miller RR, Mackowiak PA. Failure of clinical practice guidelines to meet the Institute of Medicine standards: two decades of little, if any, progress. Arch Intern Med. 2012;172(21): 1628-33.

4. Shaneyfelt T. In guidelines we cannot trust. Arch Intern Med. 2012;172(21):1633-44. 